\title{
Landscape effects of forest loss in a pollination system
}

\author{
Hisatomo Taki $\cdot$ Peter G. Kevan · John S. Ascher
}

Received: 24 February 2007/Accepted: 13 August 2007/Published online: 6 September 2007

(C) Springer Science+Business Media B.V. 2007

\begin{abstract}
Forest loss has been invoked as a cause for changes in the reproductive success of animalpollinated woodland plants, associated with changes in their pollinators. To analyze such effects, it is important to include all of the three key players: landscapes, pollinators and a plant. We investigated effects of forest loss on an insect-pollinated plant through landscapes in forested ecosystems to pollinator communities and plant populations. Then we questioned if abundance and species richness in pollinator communities decrease as forest loss increases, and this in turn leads to a decrease in reproductive output of an insect-pollinated plant. We
\end{abstract}

H. Taki · P. G. Kevan

Department of Environmental Biology, University

of Guelph, Guelph, ON, Canada N1G 2W1

P. G. Kevan

e-mail: pkevan@uoguelph.ca

H. Taki $(\square)$

Department of Forest Entomology, Forestry and Forest

Products Research Institute, 1 Matsunosato, Tsukuba,

Ibaraki 305-8687, Japan

e-mails: htaki@affrc.go.jp; htaki@uoguelph.ca

\section{J. S. Ascher}

Division of Invertebrate Zoology, American Museum of Natural History, New York, NY 10024, USA

e-mail: ascher@amnh.org made a study with 12 populations of the bee pollinated herb, Erythronium americanum, in a landscape characterized by scattered fragments of deciduous forest within intensively managed agricultural fields. We also sampled bees as the potential pollinators by pan traps. We quantified the study landscapes using the amount of forest cover and the length of forest edge within each of the six radii (250, 500, 750, 1,000, 1,250 and 1,500 m). Regression analyses showed that the abundance and species richness of all collected bees were positively related to only the forest cover at the radius of $750 \mathrm{~m}$. We also found the positive relationships for the seed set of E. americanum when the forest cover at the same radius and abundance of all collected bees were used as the predictor variables. These results indicate that forest loss causes negative impacts on potential pollinator communities and seed sets of some woodland herbs.

Keywords Apiformes - Apoidea .

Carolinian forest - Forested ecosystem .

Fragmentation - Habitat loss - Spring ephemeral

\section{Introduction}

Habitat loss is a current major threat to biodiversity, and the losses occurring within landscape scales could result in habitat fragmentation (Fahrig 2003; Ewers and Didham 2006). Landscape changes lead 
to alterations in the inter-specific interactions of organisms, such as plants and pollinators (Didham et al. 1996; Tscharntke and Brandl 2004; Aguilar et al. 2006). Plant-pollinator interactions are one of the critical services for sustainable ecosystems, so that loss of the function provided by such services can lead to extirpations and potentially to extinctions (Rathcke and Jules 1993; Buchmann and Nabhan 1996; Allen-Wardell et al. 1998; Kearns et al. 1998; Kevan 1999; Biesmeijer et al. 2006).

Several studies showed that such habitat disturbances, including both loss and fragmentation, negatively affect the sexual reproductive success of plants in forest environments (Aizen and Feinsinger 1994a; Cunningham 2000a, b; Parra-Tabla et al. 2000; Rocha and Aguilar 2001; Aguilar and Galetto 2004; Kolb 2005). Moreover, such changes in the reproductive success of plants have been shown to be accompanied by changes in the communities of their mutualistic partner, pollinators (Aizen and Feinsinger 1994b; Steffan-Dewenter and Tscharntke 1999; Steffan-Dewenter et al. 2001; Donaldson et al. 2002; Ghazoul and McLeish 2002; Murren 2002; Quesada et al. 2004). Those studies suggest that it is important to include all of the three key players: landscapes, pollinators and plants.

For such ecological studies on landscape-scale, one of these three factors, technological developments of geographic information systems (GIS), have been contributing (Turner et al. 2001), and there are few studies on pollination systems including the landscape aspect. In this study, we quantify each of the three factors within forest environments to analyze the landscape consequences of forest loss to insect pollinator communities and woodland plant populations with the aid of GIS. The main questions we asked in this study are if abundance and species richness in pollinator communities decrease as forest loss increases, and this in turn leads to a decrease in reproductive output of an insect-pollinated plant. Landscape values to represent forest loss were quantified by the amount of forest cover, simply caused by loss of forest area, and the amount of forest edge associated with forest fragmentation caused by loss of forest area. Additionally, we investigated the relationship, if any, between forest loss and flowering density of study plant populations, and between the flowering density and seed set.

\section{Methods}

Study region

Our study was made in Norfolk County, Ontario, Canada $\left(42^{\circ} 37^{\prime}-42^{\circ} 48^{\prime} \mathrm{N}, 80^{\circ} 25^{\prime}-80^{\circ} 39^{\prime} \mathrm{W}\right)$ in the Carolinian forest region of southern Ontario's deciduous forest zone, an ecosystem of limited distribution in Canada (Allen et al. 1990). The chosen landscape is rather flat and homogeneous with scattered fragments of forest patches within intensively managed agricultural fields of annual crops, mainly tobacco, corn and soybean. There are few covered by other vegetation types such as orchard fields, grazed grasslands and weedy verges. It follows that after intensive agricultural development, which started in the late 18th century, plant species found in the Carolinian forest have decreased and have been identified as being of high priority for conservation within Canada (Argus 1992; Waldron 2003).

\section{Study plant}

We selected Erythronium americanum Ker. (Liliaceae) as our model plant species. This species is bulbous, perennial, a common vernal woodland herb, widely distributed in Eastern North American forests (Gleason and Cronquist 1963). It is known as a spring ephemeral, which takesadvantage of phenology including flower bloom for the high light intensities in the early spring before leaf-out of canopy trees shading the forest understory (Holland 1974; Muller 1978; Lapointe and Lerat 2006). Sexually mature, two-leaved, plants produce a single, yellow, perfect flower.

Flowers of E. americanum are visited by numerous insect species, of which various bees are considered the potential main pollinator assemblages. These reported bee species include Osmia atriventris Cresson, Osmia lignaria Say, Lasioglossum (Dialictus) coerulum (Robertson), Andrena arabis Robertson, Andrena carlini Cockerell, Andrena erigeniae Robertson, Andrena erythronii Robertson, Andrena forbesii Robertson, Andrena tridens Robertson, Apis mellifera L., Bombus bimaculatus Cresson, and Nomada species (cleptoparasites of Andrena species) (Blanchan 1916; Michener and Rettenmeyer 1956; Bernhardt 1977; Krombein et al. 1979; Harder et al. 
$1985,1993)$. Our preliminary insect samples from the flowers in the study region included some of these reported species, as well as Lasioglossum (Lasioglossum) paraforbesii McGinley, Andrena vicina Smith, Bombus vegans Smith, Ceratina calcarata Robertson (Taki and Kevan 2007).

Among these reported and sampled bee species, we especially focused on the following three Andrena species: A. erythronii, A. carlini and A. vicina for our species-level analysis. A. erythronii is known as the specialist bee species of Erythronium (Michener and Rettenmeyer 1956). Andrena carlini is a comparably large andrenid bee and has been indicated as the primarily pollinator species of E. americanum by Harder et al. (1985, 1993). It was considered that A. vicina could also be a primarily pollinator for E. americanum because both large andrenid bees in the same subgenus Melandrena are morphologically and ecologically similar.

\section{Study sites}

In April 2005, we selected 12 populations of $E$. americanum in 12 different sites surrounded by varying amounts of forest cover, all in a 67,500 ha area of Norfolk County (Fig. 1). The criteria for accepting a site included a distance of at least 3,000 $\mathrm{m}$ from any other study populations, ensured by use of ArcView (version 3.3, ESRI, Redlands, Calif.) and global positioning system (GPS) (Garmin International, Olathe, Kan.). The geospatial data of forest cover were obtained from aerial photography $(1: 30,000$ and 1:50,000) and the Ontario Base Map Series by the Ontario Ministry of Natural Resources, Peterborough, Ontario, Canada in 2003.

On the maps, we created a circle with six radii (250, 500,750,1,000, 1,250 and 1,500 m) on an E. americanum population, which was projected by ArcView and used to measure the amount of forest cover $\left(\mathrm{m}^{2}\right)$ at each of the 12 selected site. These scales of radii were selected as being relevant to foraging distance of and landscape-scale response of bee communities (Gathmann and Tscharntke 2002; Steffan-Dewenter et al. 2002; Winfree et al. 2007). In addition to the forest cover, another landscape effect, the amount of forest edge represented by the total length $(\mathrm{m})$ within the same six radii $(250,500$, $750,1,000,1,250$ and 1,500 $\mathrm{m}$ ) was measured, using

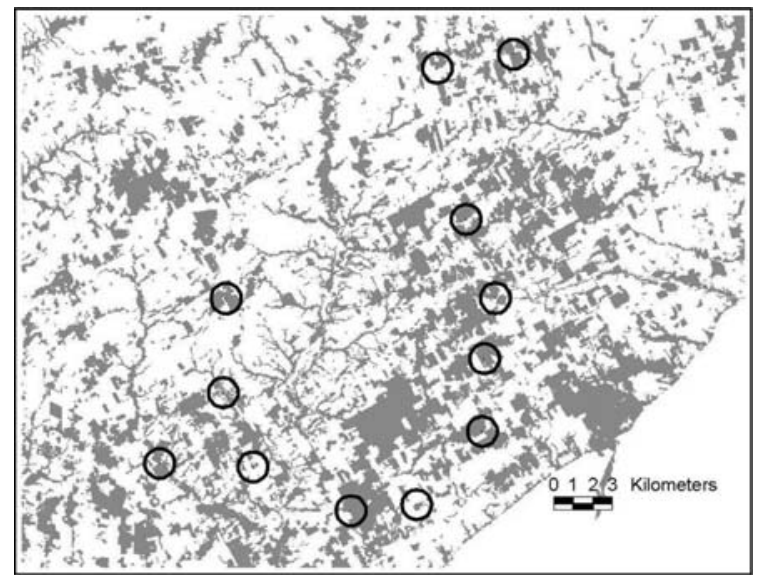

Fig. 1 Twelve study sites of E. americanum with 750-m radius used to obtain the forested landscape values, amount of forest cover and length of forest edge, in Norfolk County of Ontario, Canada. Shaded areas indicate forests. The geospatial data were obtained from the Ontario Base Map Series in 2003 (Ontario Ministry of Natural Resources, Peterborough, Ontario, Canada)

ArcView. We then investigated if there were any edge effects.

Furthermore, to see the effects of forest cover on flowering density of E. americanum, and later to check on the effects of the plant density on seed set, flowering heads within a 10 -m radius from the central point of the population were counted at each of the 12 sites on 4 and 5 May.

\section{Sampling of bees}

Three yellow bowl pan traps (diameter $=15 \mathrm{~cm}$ top $\times 6.5 \mathrm{~cm}$ base; $7 \mathrm{~cm}$ deep) with approximately $200 \mathrm{ml}$ of soapy water were used to collect the potential bee pollinator species (Potts et al. 2005). They were set out within the E. americanum populations at each of the 12 sites. The three traps for each site were randomly placed $5 \mathrm{~m}$ apart on the ground. To prevent possible disturbances by mammals and birds, all the pans were covered with metal mesh fence (1-inch chicken wire) supported by twigs. The spacing in the mesh was large enough for even the largest bees in the region (bumble bee queens) to pass through. The traps were deployed for a total of $72 \mathrm{~h}$ from 4 to 7 May on sunny days during the blooming of E. americanum. Placement of and collecting from 
the traps were done in the evenings from 18:00 to 21:00.

Different bee species and sexes within species are attracted to different colors and shapes of pan traps (Leong and Thorp 1999; Cane et al. 2000; Toler et al. 2005). It was recognized that the results may be biased through the pan traps, but the bias would be consistent among the 12 study sites.

Trapped bees were taken to the laboratory to be pinned and labeled. Specimens were identified by John Ascher and Sam Droege using standard references, reference collections at the American Museum of Natural History and the Smithsonian, and online keys available at www.discoverlife.org. Vouchers are deposited in the Department of Environmental Biology, University of Guelph. As well as analyses of all collected bees (non-cleptoparasitic females and males, and cleptoparasites), analyses of pollen-foraging bees (non-cleptoparasitic females), which were likely more important pollinators, were made. Moreover, as indicated above, analyses on A. erythronii, A. carlini and A. vicina alone were attempted for our species level analysis.

\section{Seed set}

For each of the 12 populations, we randomly selected 17 individual stalks, at least $30 \mathrm{~cm}$ from each other, of E. americanum with buds on 24 and 25 April. After blooming on 15 May, the stalks with open flowers were covered by polypropylene 3-mm-square mesh bags (product number ON-6200, InterNet, Minneapolis, Minn.) to prevent possible damage by herbivorous mammals and birds.

In addition to those open pollinated flowers, 17 individual flowering stalks were randomly selected at each site for hand self-pollinations to check for selfcompatibility in each population (Sage et al. 2005). Stalks with buds were covered with paper bags on the same days the buds were selected on 24 and 25 April. Each recipient flower's bag was opened and the flower pollinated by dusting its stigma with pollen from its own anthers by use of a wooden tooth pick. The flowers were then re-bagged. This was done 1 or 2 days after anthesis, following the protocol of Harder et al. (1985).

On 24 May, all of the swollen fruits were taken to the laboratory where they were dissected and the developed and undeveloped seeds (the latter from unfertilized ovules or aborted seeds) were counted using Wolfe's (1983) criteria. The mean percentage of seeds set was obtained by comparing the ratios of developed to aborted seeds for each of the 17 fruits for each site.

\section{Statistical analyses}

First, we made simple linear regression analyses to see effects of forest cover amount $\left(\mathrm{m}^{2}\right)$ on abundance and species richness of all collected bees and of pollen-foraging bees alone, where each of the forest covers within the six radii $(250,500,750,1,000$, 1,250 and $1,500 \mathrm{~m}$ ) was used as the predictor variable. Similarly, for the species level analyses on our selected Andrena, we made linear regression analyses on abundance of each species, where each of the forest covers within the six radii was used as the predictor variable. These and following statistical computations were done by PROC GLM of SAS (version 8.2, SAS Institute, Cary, N.C.), and a type I error rate of 0.05 was set for all of the analyses.

Second, to see if there were any edge effects, we used simple linear regression analyses to test for abundance and species richness of all collected bees and of pollen-foraging bees alone, where the amount forest edge represented by the length $(\mathrm{m})$ was used as the predictor variable. Similarly, for the species-level analyses on our selected Andrena, we made linear regression analyses on abundance of each species, where each of the forest edge lengthes within the six radii was used as the predictor variable.

Third, we made linear regression analyses for the seed set in E. americanum. Simple linear regression analyses were made to test for the seed set in E. americanum, where the amount of forest cover and length forest edge were analyzed at the six radii. We also made multiple regression analyses, where both landscape values (the amount of forest cover and the length forest edge) and bee abundances were used as the predictor variables. To select the predictor variables, we used the results from the analyses of bee community and species on the amount of forest cover and length of forest edge.

Additionally, we made regression analyses to examine the relationship, if any, between forest cover and/or forest edge and flowering density of 
E. americanum, and between the flowering density and seed set. To select the radii to measure characteristics of forested landscape, we referred the results of the radii obtained from the analyses of bee community and species on the amount of forest cover and length of forest edge.

\section{Results}

Bees

In total, 564 bee individuals were collected from the 12 study sites. Ten bees had to be excluded from analysis of species richness because they could not be identified. Of the remaining 554 individuals, 46 species were found in the families Colletidae, Megachilidae, Halictidae, Andrenidae and Apidae (Table 1). Among the 564 individuals, 208 (36.9\% of total individuals) were pollen-foraging female bees represented by 32 (69.6\% of total species) species of the families Colletidae, Halictidae, Andrenidae and Apidae (Table 1).

The regression analyses indicated significant positive relationships with the highest $R^{2}$ value between the forest cover within $750 \mathrm{~m}$ radius and abundance of all bees and their species richness, but no significant relationships were found from the forest covers within the other five radii $(250,500$, $1,000,1,250$ and 1,500 m) (Table 2). The analysis also indicated a significant positive relationship with the highest $R^{2}$ value between the forest cover at $750 \mathrm{~m}$ radius and abundance of pollen-foraging bees (Table 3). However, no significant relationships were detected between forest cover at the other five radii and abundance of pollen-foraging bees, and between forest covers at any of the six radii and species richness of pollen-foraging bees (Table 3 ).

No significances were indicated when the regression analyses were made on the abundance and species richness of both all bees and pollen-foraging bees in relation to the length of forest edge within any of the six radii (Tables 4,5).

For the species level analysis, because we collected only seven individuals of $A$. erythronii, the further analysis on the species was not made on this species. We collected 240 A. carlini and 99 A. vicina individuals. The regression analyses on the abundances on these two species showed no significances in relation to both the amount of forest cover and the length of forest edge within the six radii (Tables 6, 7).

Seed set

From the 204 hand self-pollinated flowers of E. americanum, we found no stalks with fruits expressing developed seed in any of the 12 sites.

Using the data on the open pollinated flowers, we found a significant positive relationship with the highest $R^{2}$ value between the seed set and forest cover within $750 \mathrm{~m}$ radius, but no significant relationships were found from the forest covers within the other five radii $(250,500,1,000,1,250$ and $1,500 \mathrm{~m}$ ) (Table 8 ). The analyses indicated no significances when lengths of forest edge with any of the six radii were used for the predictor of the seed set (Table 8).

Multiple leaner regression analyses for the seed set of the open pollinated flowers indicated significant positive relationships, when abundance of all bees alone, and when both forest cover and abundance of all bees together were used as the predictor variables for the seed set (Table 9). However, significant relationships were not indicated when the abundance of pollen-foraging bees was included as the predictor variable for the seed set (Table 9).

Additionally, either significant positive or negative relationships were not indicated between the number of flowering stalks and forest cover at $750 \mathrm{~m}$ radius $\left(R^{2}=0.001, F_{1,10}=0.01, P=0.917\right)$ and between the seed set and the number of flowering stalks in a population $\left(R^{2}=0.091, F_{1,10}=1.00, P=0.341\right)$.

\section{Discussion}

An assessment of all of the bees sampled by pan trap indicated that abundance and species richness were positively related to forest cover. However, the results of species richness of pollen-foraging (noncleptoparasitic female) bees and the abundance of two Andrena species, A. carlini and A. vicina, suggest that they are not affected by forest loss. None of our bee assemblages and species was affected by the effects of forest edge amount. It is still premature to conclude that forest loss adversely affects whole bee 
Table 1 Bee species and their abundance collected by yellow pan traps in Norfolk County of Ontario, Canada. Numbers and C within brackets indicate the abundance of female pollen-foraging individuals and cleptoparasitic species, respectively

\begin{tabular}{|c|c|c|}
\hline Family & Species & No. of individuals \\
\hline Colletidae & Colletes inaequalis Say & $3(3)$ \\
\hline Megachilidae & Osmia atriventris Cresson & $1(0)$ \\
\hline \multirow[t]{17}{*}{ Halictidae } & Augochlorella aurata (Smith) & $1(1)$ \\
\hline & Halictus confusus Smith & $2(2)$ \\
\hline & Halictus rubicundus (Christ) & $1(1)$ \\
\hline & Lasioglossum (Lasioglossum) coriaceum (Smith) & $5(5)$ \\
\hline & Lasioglossum (Lasioglossum) paraforbesii McGinley & $3(3)$ \\
\hline & Lasioglossum (Dialictus) coeruleum (Robertson) & $3(3)$ \\
\hline & Lasioglossum (Dialictus) cressonii (Robertson) & $1(1)$ \\
\hline & Lasioglossum (Dialictus) foxii (Robertson) & $4(4)$ \\
\hline & Lasioglossum (Dialictus) laevissimum (Smith) & $18(18)$ \\
\hline & Lasioglossum (Dialictus) lineatulum (Crawford) & $7(7)$ \\
\hline & Lasioglossum (Dialictus) nigroviride (Graenicher) & $1(1)$ \\
\hline & Lasioglossum (Dialictus) oblongum (Lovell) & $8(8)$ \\
\hline & Lasioglossum (Dialictus) perpunctatum (Ellis) & $1(1)$ \\
\hline & Lasioglossum (Dialictus) pilosum (Smith) & $3(3)$ \\
\hline & Lasioglossum (Dialictus) versans (Lovell) & $4(4)$ \\
\hline & Lasioglossum (Dialictus) sp. 1 & $1(1)$ \\
\hline & Unidentified Lasioglossum (Dialictus) & $2(2)$ \\
\hline \multirow[t]{19}{*}{ Andrenidae } & Andrena barbilabris (Kirby) & $3(3)$ \\
\hline & Andrena bisalicis Viereck & $2(0)$ \\
\hline & Andrena carlini Cockerell & $240(61)$ \\
\hline & Andrena dunningi Cockerell & $6(3)$ \\
\hline & Andrena erythrogaster (Ashmead) & $2(0)$ \\
\hline & Andrena erythronii Robertson & $7(7)$ \\
\hline & Andrena forbesii Robertson & $6(0)$ \\
\hline & Andrena frigida Smith & $2(2)$ \\
\hline & Andrena geranii Robertson & $3(3)$ \\
\hline & Andrena imitatrix Cresson & $1(0)$ \\
\hline & Andrena milwaukeensis Graenicher & $6(0)$ \\
\hline & Andrena miserabilis Cresson & $6(4)$ \\
\hline & Andrena nasonii Robertson & $29(8)$ \\
\hline & Andrena nigrihirta (Ashmead) & $1(0)$ \\
\hline & Andrena rugosa Robertson & $5(5)$ \\
\hline & Andrena sigmundi Cockerell & $1(0)$ \\
\hline & Andrena tridens Robertson & $16(16)$ \\
\hline & Andrena vicina Smith & $99(22)$ \\
\hline & Unidentified Andrena & $3(2)$ \\
\hline \multirow[t]{6}{*}{ Apidae } & Apis mellifera Linnaeus & $2(2)$ \\
\hline & Bombus bimaculatus Cresson & $1(1)$ \\
\hline & Ceratina calcarata Robertson & $9(1)$ \\
\hline & Nomada cressonii Robertson & $2(\mathrm{C})$ \\
\hline & Nomada illinoensis Robertson & $1(\mathrm{C})$ \\
\hline & Nomada luteoloides Robertson & $11(\mathrm{C})$ \\
\hline
\end{tabular}


Table 1 continued

\begin{tabular}{llr}
\hline Family & Species & No. of individuals \\
\hline & Nomada maculata Cresson & $21(\mathrm{C})$ \\
& Nomada pygmaea Cresson & $1(\mathrm{C})$ \\
& Nomada sayi Robertson & $3(\mathrm{C})$ \\
& Nomada sp 1 & $1(\mathrm{C})$ \\
& Unidentified Nomada & $5(\mathrm{C})$ \\
\hline
\end{tabular}

communities in our study region in Ontario (see Cane 2001): the sampling time was limited to the vernal flowering period and the trapping may have been biased. However, the potential functional effects of the representationally collected bees in pollination of E. americanum would be clear because our sampling was made during its blooming duration.

Winfree et al. (2007) found that abundance and species richness of bee community in southern New Jersey decrease as forest cover increase. One of the possible explanations for the differences between their results and ours is seasonal difference of the diverse forested ecosystems. Although they sampled bees from spring to summer (April-August), our study in a deciduous forest was made in only spring (beginning of May), which is before the leaf-out of the forest canopy. Understory conditions in temperate deciduous forests dramatically change from season to season (Barnes et al. 1998; Kimmins 2004): ecosystems of deciduous forest understory in different seasons are almost different ecosystems. For example, many of forest understory herbs and shrubs bloom in spring. Many of our collected bees would be depending upon these vernal flower resources in forest.

No seed set occurred on plants with flowers retained in bags and hand self-pollinated. Studies suggest that the ratio of self-incompatibility to selfcompatibility of E. americanum varies ( $0-33.3 \%$ of fruit set success), depending on population and location (Bernhardt 1977; Harder et al. 1985, 1993). The populations of E. americanum investigated seem to be self-incompatible, so out crossing followed by insect pollination would be essential for seed set.

The results from open pollinated flowers showed a significant positive relationship of forest cover at

Table 2 Relationships between the amounts of forest cover $\left(\mathrm{m}^{2}\right)$ within the six radii $(250,500,750,1,000,1,250,1,500 \mathrm{~m})$ and all collected bees in Norfolk County of Ontario, Canada

\begin{tabular}{|c|c|c|c|c|c|}
\hline Radius (m) & $a$ & $b$ & $R^{2}$ & $F$ & $P$ \\
\hline \multicolumn{6}{|l|}{ Abundance } \\
\hline 250 & 23.707 & 0.0001753 & 0.106 & 1.18 & 0.302 \\
\hline 500 & 21.194 & 0.0000576 & 0.222 & 2.86 & 0.122 \\
\hline 750 & 14.196 & 0.0000357 & 0.374 & 5.97 & 0.035 \\
\hline 1,000 & 14.437 & 0.0000213 & 0.300 & 4.28 & 0.066 \\
\hline 1,250 & 17.406 & 0.0000136 & 0.196 & 2.44 & 0.149 \\
\hline 1,500 & 21.737 & 0.0000087 & 0.123 & 1.41 & 0.263 \\
\hline \multicolumn{6}{|c|}{ Species richness } \\
\hline 250 & 8.527 & 0.0000274 & 0.063 & 0.67 & 0.433 \\
\hline 500 & 6.312 & 0.0000131 & 0.277 & 3.84 & 0.079 \\
\hline 750 & 5.619 & 0.0000071 & 0.361 & 5.65 & 0.039 \\
\hline 1,000 & 5.424 & 0.0000044 & 0.311 & 4.52 & 0.059 \\
\hline 1,250 & 5.872 & 0.0000029 & 0.215 & 2.74 & 0.129 \\
\hline 1,500 & 7.224 & 0.0000017 & 0.114 & 1.29 & 0.282 \\
\hline
\end{tabular}

Simple linear regressions for the abundance and for the species richness of all collected bees are shown. $a$ and $b$ are regression parameters 
Table 3 Relationships between the amounts of forest covers $\left(\mathrm{m}^{2}\right)$ within the six radii $(250,500,750,1,000,1,250,1,500 \mathrm{~m})$ and pollen-foraging bees in Norfolk County of Ontario, Canada

\begin{tabular}{|c|c|c|c|c|c|}
\hline Radius (m) & $a$ & $b$ & $R^{2}$ & $F$ & $P$ \\
\hline \multicolumn{6}{|l|}{ Abundance } \\
\hline 250 & 5.856 & 0.0000864 & 0.214 & 2.72 & 0.130 \\
\hline 500 & 6.594 & 0.0000240 & 0.320 & 4.71 & 0.055 \\
\hline 750 & 5.863 & 0.0000125 & 0.380 & 6.13 & 0.033 \\
\hline 1,000 & 5.752 & 0.0000076 & 0.315 & 4.60 & 0.058 \\
\hline 1,250 & 7.150 & 0.0000047 & 0.193 & 2.40 & 0.153 \\
\hline 1,500 & 9.308 & 0.0000028 & 0.103 & 1.15 & 0.308 \\
\hline \multicolumn{6}{|c|}{ Species richness } \\
\hline 250 & 5.406 & 0.0000227 & 0.077 & 0.83 & 0.382 \\
\hline 500 & 4.552 & 0.0000086 & 0.217 & 2.77 & 0.127 \\
\hline 750 & 4.774 & 0.0000040 & 0.201 & 2.51 & 0.144 \\
\hline 1,000 & 4.902 & 0.0000023 & 0.152 & 1.79 & 0.210 \\
\hline 1,250 & 4.872 & 0.0000016 & 0.123 & 1.40 & 0.265 \\
\hline 1,500 & 5.111 & 0.0000011 & 0.092 & 1.01 & 0.338 \\
\hline
\end{tabular}

Simple linear regressions for the abundance and for the species richness of pollen-foraging bees are shown. $a$ and $b$ are regression parameters

$750 \mathrm{~m}$ radius on the seed set in E. americanum. The self-incompatible populations in our study sites of $E$. americanum follow the trend found by the recent review of plant reproductive susceptibility by Aguilar et al. (2006), where they found that self-incompatible species are in fact more susceptible to reproductive impairment due to habitat loss because they are highly dependent on animal pollinators. In fact, we found significant positive relationships on the seed set of E. americanum when abundance of all collected bees alone and both the abundance and forest cover were used as the predictors. Although there is no

Table 4 Relationships between the amounts of forest edge, measured by length (m), within the six radii $(250,500,750,1,000,1,250$, $1,500 \mathrm{~m}$ ) and all collected bees in Norfolk County of Ontario, Canada

\begin{tabular}{|c|c|c|c|c|c|}
\hline Radius (m) & $a$ & $b$ & $R^{2}$ & $F$ & $P$ \\
\hline \multicolumn{6}{|l|}{ Abundance } \\
\hline 250 & 35.812 & 0.00946 & 0.068 & 0.73 & 0.412 \\
\hline 500 & 31.372 & 0.00402 & 0.117 & 1.33 & 0.276 \\
\hline 750 & 34.674 & 0.00151 & 0.050 & 0.53 & 0.485 \\
\hline 1,000 & 37.617 & 0.00066 & 0.022 & 0.23 & 0.644 \\
\hline 1,250 & 43.161 & 0.00017 & 0.002 & 0.02 & 0.883 \\
\hline 1,500 & 41.130 & 0.00019 & 0.003 & 0.03 & 0.866 \\
\hline \multicolumn{6}{|c|}{ Species richness } \\
\hline 250 & 11.822 & 0.00029 & 0.002 & 0.02 & 0.903 \\
\hline 500 & 8.941 & 0.00083 & 0.121 & 1.38 & 0.268 \\
\hline 750 & 9.253 & 0.00036 & 0.068 & 0.73 & 0.414 \\
\hline 1,000 & 9.809 & 0.00016 & 0.034 & 0.35 & 0.566 \\
\hline 1,250 & 8.947 & 0.00014 & 0.039 & 0.41 & 0.539 \\
\hline 1,500 & 7.606 & 0.00014 & 0.044 & 0.46 & 0.514 \\
\hline
\end{tabular}

Simple linear regressions for the abundance and for the species richness all collected bees are shown. $a$ and $b$ are regression parameters 
Table 5 Relationships between the amounts of forest edge, measured by length (m), within the six radii $(250,500,750,1,000,1,250$, $1,500 \mathrm{~m}$ ) and pollen-foraging bees in Norfolk County of Ontario, Canada

\begin{tabular}{|c|c|c|c|c|c|}
\hline Radius (m) & $a$ & $b$ & $R^{2}$ & $F$ & $P$ \\
\hline \multicolumn{6}{|l|}{ Abundance } \\
\hline 250 & 15.199 & 0.00181 & 0.021 & 0.21 & 0.656 \\
\hline 500 & 11.214 & 0.00157 & 0.149 & 1.76 & 0.215 \\
\hline 750 & 11.922 & 0.00066 & 0.080 & 0.87 & 0.373 \\
\hline 1,000 & 12.576 & 0.00033 & 0.047 & 0.5 & 0.496 \\
\hline 1,250 & 12.088 & 0.00024 & 0.035 & 0.37 & 0.558 \\
\hline 1,500 & 11.014 & 0.00020 & 0.029 & 0.3 & 0.598 \\
\hline \multicolumn{6}{|c|}{ Species richness } \\
\hline 250 & 7.196 & 0.00103 & 0.035 & 0.37 & 0.558 \\
\hline 500 & 4.838 & 0.00092 & 0.267 & 3.65 & 0.085 \\
\hline 750 & 5.066 & 0.00041 & 0.161 & 1.92 & 0.196 \\
\hline 1,000 & 5.250 & 0.00022 & 0.110 & 1.24 & 0.292 \\
\hline 1,250 & 4.119 & 0.00019 & 0.125 & 1.42 & 0.260 \\
\hline 1,500 & 1.838 & 0.00021 & 0.164 & 1.96 & 0.192 \\
\hline
\end{tabular}

Simple linear regressions for the abundance and for the species richness pollen-foraging bees are shown. $a$ and $b$ are regression parameters

statistical power to disentangle cause and effect among the values and similarly no manipulative experiments (like pollen hand supplementation vs. open treatment in each site) in this study, the results are nevertheless consistent with there having been an effect of forest loss on the bee abundance, which then had consequences for the seed set.
No significant relationship was however found when we used abundance of pollen-foraging bees, a subset of all collected bees to predict the seed set. More trapping methods, including pans of other colors, and direct observations on the abundance, species richness and behaviors (e.g., pollen versus nectar foraging) of flower visiting bees (e.g. Frankie

Table 6 Relationships between the amounts of forest covers $\left(\mathrm{m}^{2}\right)$ within the six radii $(250,500,750,1,000,1,250,1,500 \mathrm{~m})$ and the abundance two bee species, Andrena carlini and Andrena vicina, in Norfolk County of Ontario, Canada

\begin{tabular}{|c|c|c|c|c|c|}
\hline Radius (m) & $a$ & $b$ & $R^{2}$ & $F$ & $P$ \\
\hline \multicolumn{6}{|c|}{ Andrena carlini } \\
\hline 250 & 9.035 & 0.0000825 & 0.061 & 0.65 & 0.437 \\
\hline 500 & 9.203 & 0.0000241 & 0.102 & 1.13 & 0.312 \\
\hline 750 & 6.531 & 0.0000147 & 0.165 & 1.98 & 0.190 \\
\hline 1,000 & 6.667 & 0.0000087 & 0.132 & 1.51 & 0.247 \\
\hline 1,250 & 6.696 & 0.0000061 & 0.104 & 1.16 & 0.307 \\
\hline 1,500 & 10.602 & 0.0000032 & 0.045 & 0.47 & 0.510 \\
\hline \multicolumn{6}{|c|}{ Andrena vicina } \\
\hline 250 & 5.846 & 0.0000181 & 0.011 & 0.11 & 0.751 \\
\hline 500 & 4.820 & 0.0000077 & 0.037 & 0.38 & 0.551 \\
\hline 750 & 2.481 & 0.0000063 & 0.108 & 1.21 & 0.297 \\
\hline 1,000 & 2.845 & 0.0000035 & 0.077 & 0.84 & 0.382 \\
\hline 1,250 & 3.720 & 0.0000021 & 0.043 & 0.45 & 0.518 \\
\hline 1,500 & 2.426 & 0.0000020 & 0.061 & 0.65 & 0.438 \\
\hline
\end{tabular}

Simple linear regressions for each of the species are shown. $a$ and $b$ are regression parameters 
Table 7 Relationships between the amounts of forest edge, measured by length (m), within the six radii (250, 500, 750, 1,000, 1,250, $1,500 \mathrm{~m}$ ) and the abundance two bee species, Andrena carlini and Andrena vicina, in Norfolk County of Ontario, Canada

\begin{tabular}{|c|c|c|c|c|c|}
\hline Radius (m) & $a$ & $b$ & $R^{2}$ & $F$ & $P$ \\
\hline \multicolumn{6}{|c|}{ Andrena carlini } \\
\hline 250 & 20.789 & -0.00067 & 0.001 & 0.01 & 0.927 \\
\hline 500 & 21.076 & -0.00028 & 0.001 & 0.01 & 0.906 \\
\hline 750 & 25.922 & -0.00072 & 0.030 & 0.31 & 0.589 \\
\hline 1,000 & 30.351 & -0.00072 & 0.071 & 0.76 & 0.403 \\
\hline 1,250 & 35.579 & -0.00070 & 0.098 & 1.09 & 0.321 \\
\hline 1,500 & 41.987 & -0.00069 & 0.110 & 1.24 & 0.292 \\
\hline \multicolumn{6}{|c|}{ Andrena vicina } \\
\hline 250 & 1.925 & 0.00535 & 0.204 & 2.56 & 0.141 \\
\hline 500 & 3.095 & 0.00133 & 0.119 & 1.35 & 0.272 \\
\hline 750 & 2.628 & 0.00069 & 0.097 & 1.08 & 0.324 \\
\hline 1,000 & 1.219 & 0.00049 & 0.117 & 1.32 & 0.278 \\
\hline 1,250 & 3.704 & 0.00020 & 0.030 & 0.31 & 0.591 \\
\hline 1,500 & 0.911 & 0.00023 & 0.044 & 0.46 & 0.514 \\
\hline
\end{tabular}

Simple linear regressions for each of the species are shown. $a$ and $b$ are regression parameters

et al. 1997; Klein et al. 2002, 2003a, b; Cairns et al. 2005; Hines and Hendrix 2005) would reveal more completely representative of the entire functional group (Kevan et al. 1997; Belaoussoff et al. 2003). However, our results suggest that diverse insect species including male and cleptoparasitic (nonpollen-foraging) bees seem to be effective pollinators for E. americanum as indicated by the results of regression analyses with and without these bees.

The effects of each of our collected bee species on the pollination mechanisms of E. americanum were not considered in the detailed analyses on the pollination mechanisms. Different pollinator species vary in their pollination effectiveness. For instance,

Table 8 Relationships between seed set of E. americanum and both the amount of forest covers $\left(\mathrm{m}^{2}\right)$ and the length of forest edge (m) within the six radii $(250,500,750,1,000,1,250,1,500 \mathrm{~m})$ and in Norfolk County of Ontario, Canada

\begin{tabular}{llllll}
\hline Radius $(\mathrm{m})$ & $a$ & $b$ & $R^{2}$ & $F$ & $P$ \\
\hline Amount of forest cover & & & & & \\
250 & 15.405 & 0.0000617 & 0.087 & 0.95 & 0.352 \\
500 & 11.841 & 0.0000263 & 0.306 & 4.42 & 0.062 \\
750 & 10.118 & 0.0000147 & 0.419 & 7.22 & 0.023 \\
1,000 & 10.478 & 0.0000086 & 0.323 & 4.77 & 0.054 \\
1,250 & 12.019 & 0.0000053 & 0.200 & 2.49 & 0.145 \\
1,500 & 15.564 & 0.0000028 & 0.083 & 0.90 & 0.364 \\
Length of forest edge & & & & 0.81 & 0.390 \\
250 & 19.060 & 0.00384 & 0.075 & 0.40 & 0.541 \\
500 & 20.125 & 0.00089 & 0.038 & 0.12 & 0.737 \\
750 & 21.274 & 0.00028 & 0.012 & 0.20 & 0.663 \\
1,000 & 20.164 & 0.00024 & 0.020 & 0.00 & 0.956 \\
1,250 & 23.039 & 0.00003 & 0.0003 & 0.07 & 0.790 \\
1,500 & 27.184 & -0.00011 & 0.007 & & \\
\hline
\end{tabular}

$a$ and $b$ are regression parameters 
Table 9 Linear regressions using the forest cover $\left(X_{\text {forest }}\right)$ within $750 \mathrm{~m}$ radius and the abundance of all bees $\left(X_{\text {abee }}\right)$ and pollenforaging bees $\left(X_{\text {pfbee }}\right)$ as the predictor variables of the seed set of E. americanum $\left(Y_{\text {seed }}\right)$

\begin{tabular}{lrllll}
\hline Model & \multicolumn{1}{c}{$a$} & $b_{1}$ & $b_{2}$ & $R^{2}$ & $F$ \\
\hline$Y_{\text {seed }}=a+b_{1} X_{\text {abee }}$ & 11.442 & 0.259 & & 0.444 & 8.00 \\
$Y_{\text {seed }}=a+b_{1} X_{\text {abee }}+b_{2} X_{\text {forest }}$ & 7.735 & 0.168 & 0.0000087 & 0.536 & 5.20 \\
$Y_{\text {seed }}=a+b_{1} X_{\text {pfbee }}$ & 13.744 & 0.569 & & 0.258 & 3.48 \\
$Y_{\text {seed }}=a+b_{1} X_{\text {pfbee }}+b_{2} X_{\text {forest }}$ & 8.964 & 0.197 & 0.0000122 & 0.438 & 3.51 \\
\hline
\end{tabular}

$a, b_{1}$ and $b_{2}$ are regression parameters

the gynodioecious herb Knautia arvensis (L.) Coult. (Dipsacaceae) in Sweden is visited by both generalist and specialist flower visitors, but the specialist bee Andrena hattorfiana (Fabricius) is a more effective pollinator than are generalist visitors (Larsson 2005). Like $K$. arvensis, E. americanum is visited by diverse bee species, including a specialist, A. erythronii (Michener and Rettenmeyer 1956), and numerous generalists (Blanchan 1916; Bernhardt 1977; Krombein et al. 1979; Harder et al. 1985, 1993). This suggests that although only seven A. erythronii individuals were found, indicating that it may not be playing the most important role in pollinating E. americanum, in our study region, it would be interesting to investigate the populations of A. erythronii and their pollination effectiveness for E. americanum.

We found, regardless of forest cover, seed set was not influenced by density of flowering stalks of $E$. americanum, which was also uninfluenced by forest cover at the radius of $750 \mathrm{~m}$. Other researchers have found the seed sets of self-incompatible plants are affected positively and negatively or not affected by population densities and sizes (e.g., Agren 1996; Kunin 1997; Molano-Flores and Hendrix 1999; Forsyth 2003; Waites and Agren 2004; Kirchner et al. 2005). Their results, and the findings, suggest that the landscapes surrounding each population are more important than plant density or size, or both of insect pollinated-plants in influencing seed set. Our analyses indicate that forest loss has significantly negative impacts on bee communities (i.e., the potential pollinators) and seed sets in populations of self-incompatible populations of E. americanum, which potentially could lead to local extirpation of sensitive bee species and the plant. Although the population densities of the study plants presently are unaffected by landscape change, it is suggested that over time a senescing and obligately out-crossing population with diminished sexual reproductive output would be in jeopardy.

Acknowledgements We thank Long Point Conservation Authority, M. Armstrong, J. DeCloet and J. Knack for access to the study sites. We also thank B. Viana, F. Silva, J. Trevors and G. Umphrey for discussion, A. Pawlowski, K. Ferguson and R. Barbero for their assistance with the field and laboratory work, A. Manceur and V. MacPhail for their assistance with the field sampling, A. Serafin for supplying plant mesh covering, C. Connell and Q. Shirk-Luckett for GIS support and S. Droege for identifying Lasioglossum (Dialictus) bees. This work was supported by a scholarship from the Rotary Foundation to H. Taki and a grant from the Natural Sciences and Engineering Research Council of Canada to P.G. Kevan.

\section{References}

Agren J (1996) Population size, pollinator limitation, and seed set in the self-incompatible herb Lythrum salicaria. Ecology 77:1779-1790

Aguilar R, Galetto L (2004) Effects of forest fragmentation on male and female reproductive success in Cestrum parqui (Solanaceae). Oecologia 138:513-520

Aguilar R, Ashworth L, Galetto L et al (2006) Plant reproductive susceptibility to habitat fragmentation: review and synthesis through a meta-analysis. Ecol Lett 9:968-980

Aizen MA, Feinsinger P (1994a) Forest fragmentation, pollination, and plant reproduction in a Chaco dry forest, Argentina. Ecology 75:330-351

Aizen MA, Feinsinger P (1994b) Habitat fragmentation, native insect pollinators, and feral honey bees in Argentina Chaco Serrano. Ecol Appl 4:378-392

Allen GM, Eagles PFJ, Price SD (eds) (1990) Conserving Carolinian Canada. University of Waterloo Press, Waterloo

Allen-Wardell G, Bernhardt P, Bitner R et al (1998) The potential consequences of pollinator declines on the conservation of biodiversity and stability of food crop yields. Conserv Biol 12:8-17

Argus GW (1992) The phytogeography of rare vascular plants in Ontario and its bearing on plants conservation. Can J Bot 70:469-490 
Barnes BV, Zak DR, Denton SR et al (1998) Forest ecology, 4th edn. John Wiley \& Sons Inc., New York

Belaoussoff S, Kevan PG, Murphy S et al (2003) Assessing tillage disturbance on assemblages of ground beetles (Coleoptera: Carabidae) by using a range of ecological indices. Biodivers Conserv 12:851-882

Bernhardt P (1977) The pollination ecology of a population of Erythronium americanum Ker (Liliaceae). Rhodora 79:278-282

Biesmeijer JC, Roberts SP, Reemer M et al (2006) Parallel declines in pollinators and insect-pollinated plants in Britain and the Netherlands. Science 313:351-354

Blanchan N (1916) Wild flowers: an aid to knowledge of our wild flowers and their insect visitors. Doubleday, Page \& Company, New York

Buchmann SL, Nabhan GP (1996) The forgotten pollinators. Island Press, Washington DC

Cairns CE, Villanueva-Gutierrez R, Koptur S et al (2005) Bee populations, forest disturbance, and africanization in Mexico. Biotropica 37:686-692

Cane JH (2001) Habitat fragmentation and native bees: a premature verdict? Conserv Ecol 5:3. Available from http:// www.consecol.org/vol5/iss1/art3 (accessed February 2007).

Cane JH, Minckley RL, Kervin LJ (2000) Sampling bees (Hymenoptera: Apiformes) for pollinator community studies: pitfalls of pan-trapping. J Kans Entomol Soc 73:225-231

Cunningham SA (2000a) Depressed pollination in habitat fragments causes low fruit set. Proc R Soc Lond Ser B Biol Sci 267:1149-1152

Cunningham SA (2000b) Effects of habitat fragmentation on the reproductive ecology of four plant species in mallee woodland. Conserv Biol 14:758-768

Didham RK, Ghazoul J, Stork NE et al (1996) Insects in fragmented forests: a functional approach. Trend Ecol Evol 11:255-260

Donaldson J, Nanni I, Zachariades C et al (2002) Effects of habitat fragmentation on pollinator diversity and plant reproductive success in renosterveld shrublands of South Africa. Conserv Biol 16:1267-1276

Ewers RM, Didham RK (2006) Confounding factors in the detection of species responses to habitat fragmentation. Biol Rev 81:117-142

Fahrig L (2003) Effects of habitat fragmentation on biodiversity. Annu Rev Ecol Syst 34:487-451

Forsyth SA (2003) Density-dependent seed set in the Haleakala silversword: evidence for an Allee effect. Oecologia 136:551-557

Frankie GW, Vinson SB, Rizzardi MA et al (1997) Diversity and abundance of bees visiting a mass flowering tree species in disturbed seasonal dry forest, Costa Rica. J Kans Entomol Soc 70:281-296

Gathmann A, Tscharntke T (2002) Foraging ranges of solitary bees. J Anim Ecol 71:757-764

Ghazoul J, McLeish M (2002) Reproductive ecology of tropical forest trees in logged and fragmented habitats in Thailand and Costa Rica. Plant Ecol 153:335-345

Gleason HA, Cronquist A (1963) Manual of vascular plants of northeastern United States and adjacent Canada. Van Nostrand, New York
Harder LD, Thomson JD, Cruzan MB et al (1985) Sexual reproduction and variation in floral morphology in an ephemeral vernal lily, Erythronium americanum. Oecologia 67:286-291

Harder LD, Cruzan MB, Thomson JD (1993) Unilateral incompatibility and the effects of interspecific pollination for Erythronium americanum and Erythronium albidum (Liliaceae). Can J Bot 71:353-358

Hines HM, Hendrix SD (2005) Bumble bee (Hymenoptera: Apidae) diversity and abundance in tallgrass prairie patches: effects of local and landscape floral resources. Environ Entomol 34:1477-1484

Holland PG (1974) The growth, behavior, ecology and geography of Erythronium americanum in Northeast North America. Can J Bot 52:1765-1772

Kearns CA, Inouye DW, Waser NM (1998) Endangered mutualisms: the conservation of plant-pollinator interactions. Annu Rev Ecol Syst 29:83-112

Kevan PG (1999) Pollinators as bioindicators of the state of the environment: species, activity and diversity. Agric Ecosyst Environ 74:373-393

Kevan PG, Greco CF, Belaoussoff S (1997) Log-normality of biodiversity and abundance in diagnosis and measuring of ecosystemic health: pesticide stress on pollinators on blueberry heaths. J Appl Ecol 34:1122-1136

Kimmins JP (2004) Forest ecology: a foundation for sustainable forest management and environmental ethics in forestry, 3rd edn. Pearson Prentice Hall, Upper Saddle River

Kirchner F, Luijten SH, Imbert E et al (2005) Effects of local density on insect visitation and fertilization success in the narrow-endemic Centaurea corymbosa (Asteraceae). Oikos 111:130-142

Klein AM, Steffan-Dewenter I, Buchori D et al (2002) Effects of land-use intensity in tropical agroforestry systems on coffee flower-visiting and trap-nesting bees and wasps. Conserv Biol 16:1003-1014

Klein AM, Steffan-Dewenter I, Tscharntke T (2003a) Fruit set of highland coffee increases with the diversity of pollinating bees. Proc R Soc Lond Ser B Biol Sci 270:955-961

Klein AM, Steffan-Dewenter I, Tscharntke T (2003b) Pollination of Coffea canephora in relation to local and regional agroforestry management. J Appl Ecol 40:837845

Kolb A (2005) Reduced reproductive success and offspring survival in fragmented populations of the forest herb Phyteuma spicatum. J Ecol 93:1226-1237

Krombein KV, Hurd PD, Smith DR et al (1979) Catalog of Hymenoptera in America north of Mexico, Volume 2 Apocrita (Aculeata). Smithsonian Institution Press, Washington DC

Kunin WE (1997) Population size and density effects in pollination: pollinator foraging and plant reproductive success in experimental arrays of Brassica kaber. J Ecol $85: 225-234$

Lapointe L, Larat S (2006) Annual growth of the spring ephemeral Erythronium americanum as a function of temperature and mycorrhizal status. Can J Bot 84:39-48

Larsson M (2005) Higher pollinator effectiveness by specialist than generalist flower-visitors of unspecialized Knautia arvensis (Dipsacaceae). Oecologia 146:394-403 
Leong JM, Thorp RW (1999) Colour-coded sampling: the pan trap colour preferences of oligolectic and nonoligolectic bees associated with a vernal pool plant. Ecol Entomol 24:329-335

Michener CD, Rettenmeyer CW (1956) The ethology of Andrena erythronii with comparative data on other species. Univ Kans Sci Bull 37:645-684

Molano-Flores B, Hendrix SD (1999) The effects of population size and density on the reproductive output of Anemone canadensis L. (Ranunculaceae). Int J Plant Sci 160:759766

Muller RN (1978) The phenology, growth and ecosystem dynamics of Erythronium americanum in the northern hardwood forest. Ecol Monogr 48:1-20

Murren CJ (2002) Effects of habitat fragmentation on pollination: pollinators, pollinia viability and reproductive success. J Ecol 90:100-107

Parra-Tabla V, Vargas CF, Magana-Rueda S et al (2000) Female and male pollination success of Oncidium ascendens Lindey (Orchidaceae) in two contrasting habitat patches: forest vs agricultural field. Biol Conserv 94:335-340

Potts SG, Kevan PG, Boone JW (2005) Conservation in pollination: collecting, surveying and monitoring. In: Dafni A, Kevan PG, Husband BC (eds) Practical pollination biology. Enviroquest, Cambridge, pp 401-434

Quesada M, Stoner KE, Lobo JA et al (2004) Effects of forest fragmentation on pollinator activity and consequences for plant reproductive success and mating patterns in bat-pollinated bombacaceous trees. Biotropica 36:131-138

Rathcke BJ, Jules ES (1993) Habitat fragmentation and plantpollinator interactions. Curr Sci 65:273-277

Rocha OJ, Aguilar G (2001) Reproductive biology of the dry forest tree Enterolobium cyclocarpum (Guanacaste) in Costa Rica: a comparison between trees left in pastures and trees in continuous forest. Am J Bot 88:1607-1614
Sage TL, Husband BC, Routley MB (2005) Intrinsic attributes of the breeding system. In: Dafni A, Kevan PG, Husband BC (eds) Practical pollination biology. Enviroquest, Cambridge, pp 27-55

Steffan-Dewenter I, Tscharntke T (1999) Effects of habitat isolation on pollinator communities and seed set. Oecologia 121:432-440

Steffan-Dewenter I, Münzenberg U, Tscharntke T (2001) Pollination, seed set and seed predation on a landscape scale. Proc R Soc Lond Ser B Biol Sci 268:1685-1690

Steffan-Dewenter I, Münzenberg U, Bürger C et al (2002) Scale-dependent effects of landscape context on three pollinator guilds. Ecology 83:1421-1432

Taki H, Kevan PG (2007) Does habitat loss affect the communities of plants and insects equally in plant-pollinator interaction? Preliminary findings. Biodiver Conserv 16:3147-3161

Toler TR, Evans EW, Tepedino VJ (2005) Pan-trapping for bees (Hymenoptera: Apiformes) in Utah's west desert: the importance of color diversity. Pan-Pac Entomol 81:103113

Tscharntke T, Brandl R (2004) Plant-insect interactions in fragmented landscapes. Annu Rev Entomol 49:405-430

Turner MG, Gardner RH, O’Neill RV (2001) Landscape ecology in theory and practice. Springer, Now York

Waites AR, Agren J (2004) Pollinator visitation, stigmatic pollen loads and among-population variation in seed set in Lythrum salicaria. J Ecol 92:512-526

Waldron G (2003) Trees of the Carolinian forest: a guide to species, their ecology and uses. Boston Mills Press, Toronto

Winfree R, Griswold T, Kremen C (2007) Effect of human disturbance on bee communities in a forested ecosystem. Conserv Biol 21:213-223

Wolfe LM (1983) The effect of plant size on reproductive characteristics in Erythronium americanum (Liliaceae). Can J Bot 61:3489-3493 